\title{
Bases farmacomicrobiológicas del tratamiento antibiótico de las enfermedades periodontales y periimplatarias
}

\author{
LIÑARES $\mathrm{J}$ * \\ MARTÍN-HERRERO JE **
}

\begin{abstract}
Liñares J, Martín-Herrero JE. Bases farmacomicrobiológicas del tratamiento antibiótico de las enfermedades periodontales y periimplantarias. Av Periodon Implantol. 2003; 15, 3: 139-147.
\end{abstract}

\begin{abstract}
RESUMEN
La enfermedad periodontal debe considerarse un proceso infeccioso bacteriano crónico. En su etiología, no hay una única especie bacteriana implicada, sino que podríamos considerarla como una infección polimicrobiana en la que estarían implicados diversos microorganismos. Las bacterias que se han asociado más directamente con la enfermedad periodontal son Actinobacillus actinomycetemcomitans, Porphyromonas gingivalis, Prevotella intermedia, Bacteroides forsythus y Treponema denticola. Los parámetros farmacodinámicos de los antibióticos son muy útiles a la hora de seleccionar pautas posológicas. El aumento de resistencias producido en muchos periodontopatógenos en los últimos años ha relegado a algunos antibióticos a un segundo plano. Entre la gran variedad de antibióticos utilizados, se han obtenido buenas respuestas terapéuticas con amoxicilina/ácido clavulánico, metronidazol, clindamicina, doxiciclina y las combinaciones de metronidazol más amoxicilina y metronidazol más amoxicili-na/ácido clavulánico.
\end{abstract}

\section{PALABRAS CLAVE}

Enfermedad periodontal, antibióticos, resistencia, farmacodinamia.

\section{INTRODUCCIÓN}

La cavidad oral forma un complejo ecosistema compuesto por más de 500 especies bacterianas, en el que podemos encontrar simultáneamente bacterias residentes, algunas de las cuales son exclusivas de esta localización, y bacterias ocasionales (1). Globalmente, los géneros Streptococcus, Peptostrep-tococcus, Veillonella, Lactobacillus, Corynebacte-rium y Actinomyces representan más del $80 \%$ de toda la flora cultivable (2). Los bacilos gramnegativos facultativos son raros en adultos sanos, viéndose casi exclusivamente en pacientes con enfermedades severas, hospitalizados y ancianos (3).

La proporción de una determinada especie bacteria- na varía en función de la región anatómica que consideremos. Así por ejemplo en la superficie dental las especies predominantes son Streptococcus sanguis, Streptococcus mutans, Streptococcus mitis y Actinomyces viscosus. En cambio, Streptococcus salivarius y Veillonella spp tienen predisposición por la lengua y la mucosa oral y Fusobacterium spp, Porphyromonas spp, Prevotella spp y espiroquetas anaerobias por el surco gingival (2). Diversos factores se han implicado en este tropismo bacteriano, como son la adherencia selectiva de algunas bacterias por determinados tipos de células, tensión de oxígeno, potencial de oxidación-reducción, pH, etc. Aparte de estas consideraciones anatómicas, hay otra serie de factores que pueden influir en el ecosistema bucal, tales como la edad, dieta, higiene oral, presencia de

\footnotetext{
* Servicio de Microbiología. Hospital Universitario de Bellvitge

** Dto. Médico. GlaxoSmithKline, S.A.
} 
caries o enfermedad periodontal, tratamiento antimicrobiano, hospitalización, embarazo y factores genéticos y raciales $(2,4)$.

\section{AGENTES ETIOLÓGICOS IMPLICADOS EN LAS ENFERMEDADES PERIODONTALES}

La enfermedad periodontal es un proceso inflamatorio que se produce en los tejidos circundantes de los dientes como respuesta a una acumulación de bacterias (placa dental) sobre los dientes (5). Independientemente de que exista predisposición genética (síndrome de Papillon-LeFevre o síndrome de Down), o de que en determinados casos se asocie a cierta inmodepresión del huesped por defectos en los neutrófilos como ocurre en la periodontitis juvenil localizada, o de que haya estado favorecida por diversos factores como la condición de fumador o la mala higiene bucal, la sintomatología clínica casi siempre se asocia significativamente al sobrecrecimiento de un determinado número de especies anaerobias en la placa subgingival, por lo que debe considerarse una enfermedad infecciosa bacteriana crónica (6).

Hay una serie de hechos que respaldan claramente el origen infeccioso de la enfermedad como son: a) mejora clínica tras la eliminación de las bacterias subgingivales; b) modelos animales en los que se ha demostrado la destrucción periodontal por bacterias; c) respuesta inmune celular y producción de anticuerpos específicos frente a las bacterias asociadas a periodontitis.

En la etiología de la enfemedad peridontal no hay una única especie bacteriana implicada, sino que podríamos considerarla como una infección polimicrobiana en la que están implicados diversos microorganismos, bien en combinación en un mismo periodo de tiempo, bien de una forma secuencial. Entre las bacterias que se han implicado más directamente en la patogenia de la enfermedad periodontal estarían Actinobacillus actinomycetemcomitans, Porphyromonas gingivalis, Prevotella intermedia, Bacteroides forsythus y Treponema denticola (6). Otras especies bacterianas como Prevotella nigrescens, Campylobacter rectus, Peptostreptococcus micros, Eikenella corrodens, Fusobacterium nucleatum, etc, tienen un papel menos relevante, aunque ocasionalmente se han relacionado con algunas formas de enfermedad periodontal.

P. gingivalis y $A$. actinomycetemcomitans se han asociado con las formas progresivas de periodontitis (7), destacando el papel de $P$. gingivalis en la patogenia de la periodontitis rápidamente progresiva. $A$. actinomy- cetemcomitans y $P$. intermedia serían las bacterias predominantes en la forma localizada de la periodontitis juvenil $(7,8,9)$.

Por lo que se refiere a la periodontitis del adulto, una gran variedad de bacterias han demostrado su participación en la enfermedad. Sin embargo, $P$. gingivalis es la que parece jugar el papel más destacado $(10,11$, 12).

En resumen se puede concluir que la enfermedad periodontal tiene una etiología polimicrobiana, en la que estarían implicadas un gran número de especies bacterianas, principalmente anaerobios y bacterias microaerófilas.

\section{ANTIBIÓTICOS. BASES FARMACODINÁMICAS}

La farmacología de los antimicrobianos podemos dividirla en dos componentes: la farmacocinética y la farmacodinamia. Cuando hablamos de las características farmacocinéticas de un fármaco nos estamos refiriendo a su absorción, distribución, metabolismo y eliminación, factores que unidos al régimen posológico determinan la concentración que alcanza el fármaco en el suero y en los tejidos a lo largo del tiempo Por su parte, la farmacodinamia se ocupa de la interrelación entre las concentraciones séricas del antibiótico y su actividad antimicrobiana para un determinado microorganismo, utilizando como medida de esta última la concentración mínima inhibitoria (CMI) del antibiótico para el microorganismo en estudio (13).

Según su actividad y duración del efecto, los antimicrobianos se clasifican en 2 grandes grupos: concentración-dependientes y tiempo-dependientes. El primer grupo estaría representado por los aminoglucósidos, fluoroquinolonas, azitromicina y vancomicina, antimicrobianos con prolongado efecto postantibiótico (el efecto antibiótico persiste durante varias horas, aun cuando su concentración esté por debajo de la CMI) y cuyo efecto bactericida se incrementa a medida que aumenta la concentración del antimicrobiano (14). Esta es la razón por la cual está justificado el empleo de los aminoglucósidos en una dosis al día, que produce una eficacia similar a la del esquema clásico de dosificación, pero con un coste más bajo y con menor toxidicad. En el segundo grupo se incluirían los betalactámicos (penicilinas, cefalosporinas,...), macrólidos (eritromicina, claritromicina) y clindamicina, siendo lo fundamental en este grupo mantener concentraciones ligeramente superiores a la CMI durante el mayor tiempo posible. En este grupo de 
antibióticos, concentraciones mayores de 4-5 veces la CMI generalmente no se traducen en un mayor efecto bactericida (13). Por esta razón, cuando se administran penicilinas, clindamicina, eritromicina, etc es importante la prescripción de una posología (tanto en dosis como en número de tomas) acorde a las característica farmacocinéticas del antibiótico, con el fin de mantener durante el mayor tiempo posible concentraciones adecuadas.

En función del tipo de antibiótico, hay una serie de parámetros farmacodinámicos que se correlacionan con la eficacia bacteriológica y clínica, y que pueden utilizarse para seleccionar antibióticos y pautas posológicas con la máxima capacidad de erradicación y el mínimo potencial para desarrollar resistencias $(15,16$, 17). Los parámetros farmacodinámicos que más se correlacionan con la eficacia clínica y bacteriológica en los antibióticos concentración-dependientes son por un lado el cociente resultante al dividir el área bajo la curva de concentración sérica de 24 horas del antibiótico por la CMI del microorganismo $\left(\mathrm{ABC}_{24 \mathrm{~h}} / \mathrm{CMI}\right)$ que predice eficacia bacteriológica y clínica de aminoglucósidos, fluoroquinolonas, azitromicina, telitromicina, vancomicina, tetraciclinas y quinupristina/dalfopristina y por otro el cociente inhibitorio, que no es más que el resultado de dividir la concentración sérica máxima del antibiótico por la CMI del microorganismo ( $\left.\mathrm{C}_{\max } / \mathrm{CMI}\right)$ y que predice eficacia de fluoroquinolonas y aminoglucósidos $(13,18)$. En ambos casos, únicamente debe considerarse la proporción de antibiótico no unido a proteínas o antibiótico libre (14). Diferentes estudios realizados tanto en animales como en humanos con fluoroquinolonas han mostrado que mientras que en infecciones por bacilos gramnegativos son necesarios valores de $\mathrm{ABC}_{24 \mathrm{~h}} / \mathrm{CMI}$ superiores a 100-125 para predecir eficacia terapéutica (19), en infecciones por grampositivos (sobre todo en neumococo) serían suficientes índices por encima de 25-30 $(17,20,21)$.

Con respecto a los antibióticos tiempo-dependientes, el parámetro que mejor se correlaciona con eficacia terapéutica es el tiempo que la concentración del antibiótico permanece por encima de la CMI del microorganismo entre dos dosis ( $\mathrm{T}>\mathrm{CMI})$. Datos procedentes de estudios realizados tanto en animales como en humanos confirman que el tiempo durante el cual la concentración sérica libre de antibiótico debe estar por encima de la CMI del microorganismo ( $\mathrm{T}>\mathrm{CMI}$ ) es de un $40 \%$ para penicilinas y de un $40-50 \%$ para cefalosporinas y macrólidos $(13,22)$.

Los parámetros farmacodinámicos también son de utilidad a la hora de seleccionar pautas posológicas. Tan importante es la selección del antibiótico correcto como la de su posología, la cual debería adecuarse al nivel local de resistencias.

\section{ANTIBIÓTICOS E INFECCIONES ODONTÓGENAS}

A grandes rasgos, el tratamiento de la enfermedad periodontal podríamos dividirlo por un lado en tratamiento mecánico y por otro en tratamiento con antimicrobianos sistémicos o tópicos (6). Debido a las características de esta revisión, nos ocuparemos exclusivamente del tratamiento con antibióticos sistémicos.

El antibiótico ideal para tratar una infección debe reunir una serie de características, como son: a) activo frente a los microorganismos involucrados en el proceso infeccioso; b) evitar la aparición de resistencias; c) adecuados parámetros farmacocinéticos; d) buena penetración y difusión en el lugar de la infección y e) buena tolerancia y pocos efectos adversos.

El componente polimicrobiano de las enfermedades odontógenas en general, y de la enfermedad periodontal en particular hace recomendable en muchos casos la utilización de antibióticos con actividad frente a bacterias aerobias y frente a bacterias anaerobias, lo cual conlleva que muchos de los antibióticos disponibles no sean adecuados para el tratamiento de estas infecciones o que sea necesario la combinación de compuestos para obtener un espectro de actividad mayor y más adecuado al tipo de infección. Entre la gran variedad de antibióticos que se han utilizado en la periodontitis o en infecciones mixtas de la cavidad oral destacan: penicilina, amoxicilina, amoxicilina/ácido clavulánico, cefalosporinas, doxiciclina, metronidazol, clindamicina y macrólidos (23).

La penicilina, la ampicilina y la amoxicilina han sido clásicamente los antibióticos más utilizados en el tratamiento de las infecciones odontógenas, debido a su buena actividad que muestran frente a las bacterias aerobias y anaerobias de la cavidad oral (24). Sin embargo, en los últimos años se están viendo relegadas a un segundo plano como consecuencia del incremento del número de bacterias productoras de betalactamasas, enzimas capaces de hidrolizar las penicilinas y de ocasionar por lo tanto fracaso terapéutico $(25,26,27)$. Entre las principales bacterias productoras de betalactamasas que podemos encontrar en la cavidad oral destacan Porphyromonas spp, Prevotella spp, A. actinomycetemcomitans, Eikenella corrodens y Bacteroides spp. La ampicilina y la amoxicilina amplían el espectro de la penicilina, especialmente a bacilos gramnegativos entéricos. Desde un punto de vista farmacocinético, la amoxicilina tiene la ventaja sobre la ampicilina de que su absorción entérica es superior (60-80\% frente a 30 $55 \%$ ) (28).

La asociación de una penicilina con un inhibidor de betalactamasas reestablece la actividad de la primera frente a bacterias productoras de betalactamasas 


\section{TABLA 1.- BACTERIOLOOGÍA DE LAS ENFERIMEDADES PERIODONTALESY PERIIMPLANTARIAS}

\begin{tabular}{|c|c|}
\hline FORMAS CLÍNICAS DE ENFERMEDAD PERIODONTAL & BACTERIAS PREDOMINANTES \\
\hline Periodontitis rápidamente progresiva & $\begin{array}{c}\text { P. gingivalis } \\
\text { A. actinomycetemcomitans }\end{array}$ \\
\hline Periodontitis juvenil localizada & $\begin{array}{c}\text { A. actinomycetemcomitans } \\
\text { P. intermedia }\end{array}$ \\
\hline Periodontitis del adulto & $\begin{array}{c}\text { P. gingivalis } \\
\text { Prevotella intermedia } \\
\text { Bacteroides forsythus } \\
\text { Peptostreptococcus micros } \\
\text { Campylobacter rectus } \\
\text { Treponema denticola }\end{array}$ \\
\hline Periodontitis asociada a infección por VIH & P. gingivalis \\
\hline Enfermedad periimplantaria (56) & $\begin{array}{l}\text { Espiroquetas } \\
\text { P. micros } \\
\text { Fusobacterium spp } \\
\text { Enterobacterias } \\
\text { P. gingivalis }\end{array}$ \\
\hline
\end{tabular}

(29). El único disponible con formulación oral en España es la amoxicilina/ácido clavulánico. Por su espectro de actividad, tanto frente a bacterias aerobias como anaerobias es un antibiótico de primera linea para el tratamiento de una gran variedad de infecciones, entre las que se incluyen las infecciones odontógenas (23). Sus características farmacocinéticas le permiten conseguir concentraciones en el fluido gingival similares a las alcanzadas en suero (30). En relación a la posología, en el tratamiento de infecciones odontógenas agudas en los que pueda existir sospecha de implicación por parte de estreptococos del grupo viridans, estaría recomendado administrar dosis altas (875/125 mg/8h) (31) debido a los cambios observados en los niveles de resistencia de estas bacterias en los últimos años $(32,33,34)$.

Las cefalosporinas tiene el inconveniente de presentar mínima actividad frente a bacterias anaerobias, y muy especialmente frente a anerobios gramnegativos. Las únicas que tienen actividad anaerobicida son las cefamicinas (cefoxitina, cefminox y cefotetán), pero tienen el inconveniente de carecer de formas orales de administración. Las cefalosporinas se clasifican en generaciones, atendiendo a su espectro antibacteriano, y sin guardar relación temporal con su síntesis. En lineas generales, a medida que avanzamos en generaciones, mejora la actividad frente a gramnegativos pero empeora frente a grampositivos (29).

Doxiciclina es la tetraciclina más utilizada actualmente en odontología, siendo útil entre otros cuadros en la periodontitis juvenil localizada y en la periodontitis del adulto. Las tetraciclinas son antibióticos bacteriostáticos que presentan actividad frente a bacterias aerobias y anaerobias. Sin embargo en los últimos años han experimentado un aumento en su prevalencia de resistencia a las bacterias periodontopatógenas (35), especialmente en países como España donde el consumo de antibióticos está entre los más altos de Europa. Las tetraciclinas deben evitarse durante los primeros 8 años de vida por la posiblidad de coloración dental que conlleva su consumo a estas edades.

Los nitroimidazoles (metronidazol, ornidazol y tinidazol) son antibióticos que presentan muy buena actividad frente a bacilos gramnegativos anaerobios y espiroquetas. Sin embargo tienen el inconveniente de carecer de actividad frente a bacterias aerobias y cocos anaerobios de la cavidad oral, motivo por el cual es recomendable que se asocie con otro antibiótico en el tratamiento de algunos procesos infecciosos de origen odontógeno, especialmente en aquéllos de carácter agudo, donde la etiología suele ser mixta. Tampoco posee actividad frente a Actinomyces spp. Se ha utilizado asociado entre otros a amoxicilina y espiramicina.

La clindamicina continua siendo el tratamiento de elección en pacientes alérgicos a betalactámicos (23). Presentan buena actividad frente a bacterias anaerobias, aunque en los últimos años se viene observando 
un aumento en las tasas de resistencia de algunas especies de Bacteroides spp. Además, más de un $25 \%$ de los estreptococos del grupo viridans presentan resistencia de alto nivel ( ), no superable con altas dosis de dicho antibiótico. Tampoco es activa frente contra algunos bacilos gramnegativos como A. actinomycetemcomitans, Eikenella corrodens y Capnocytophaga spp $(37,38,39)$.

Los macrólidos son antibióticos bacteriostáticos cuya actividad frente a bacterias anaerobias es menor que la que presentan otros antibióticos como metronidazol o amoxicilina/ácido clavulánico, con tasas de resistencia muy importantes en Prevotella spp, Bacteroides spp, Porphyromonas spp, Fusobacterium spp etc (37). También presentan una menor actividad frente a bacterias aerobias, con aproximadamente un $50 \%$ de resistencia en estreptococos del grupo viridans (36), porcentaje que puede incrementarse a cifras por encima del $90 \%$ en determinadas áreas (40). Además, el fenotipo de resistencia más frecuente en nuestro medio de este grupo bacteriano es el constitutivo (36), que confiere resistencia de alto nivel a todos los macrólidos y clindamicina. El principal representante de esta familia es la eritromicina. A lo largo de la última década han aparecido nuevos representantes como azitromicina y claritromicina. Entre las ventajas que presentan estas nuevas moléculas, estarían una acción más prolongada, mayor estabilidad al medio ácido y mejor distribución en tejidos. En cuanto al espectro, claritromicina presenta una mayor actividad in vitro que el resto frente a anaerobios grampositivos, y azitromicina frente a anaerobios gramnegativos.

\section{SENSIBILIDADD DE LĀS BACTERIAS IMPLICADAAS A LOS ANTIMICROBIANOS}

Como ha ocurrido en otros campos de la Microbiología, la presión selectiva ejercida por los antibióticos ha llevado a un aumento sostenido de las tasas de resistencia en algunas especies bacterianas $(41,42)$. Aparte del consumo antibiótico, hay otros factores que favorecen la diseminación de las resistencias, como es la transferencia horizontal de material genético que codifica determinados mecanismos de resistencia entre diferentes especies y géneros bacterianos que ocupan el mismo nicho ecológico (43).

En los últimos 10-15 años se ha duplicado el número de microorganismos resistentes de la cavidad oral (43). Como ejemplo hay estudios que han puesto de manifiesto la presencia de especies productoras de betalactamasas en el $74-88 \%$ de pacientes con peridontitis $(42,44)$. En la tabla 2 se muestra la actividad de varios antimicrobianos frente a los principales periodontopatógenos.

\section{Actinobacillus actinomycetemcomitans}

Amoxiclina/ácido clavulánico y tetraciclinas muestran buena actividad frente a este bacilo gramnegativo aerobio, con tasas de resistencia prácticamente nulas para el primero y por debajo del 5\% en el caso del segundo (45). En el caso de penicilina las tasas de resistencia se aproximan al 50\% de las cepas. La actividad de los macrólidos es variable, con prevalencias de resistencia que oscilan entre el 18\% de claritromicina y el $90 \%$ de espiramicina (45). Finalmente, tanto

\begin{tabular}{|c|c|c|c|c|c|c|}
\hline & \multicolumn{6}{|c|}{$\begin{array}{l}\text { TABLA 2.- ACTIVIDAD DE VARIOS ANTIMICROBIANOS FRENTE A } \\
\text { PERIODONTOPATÓGENOS }\end{array}$} \\
\hline & $\begin{array}{c}\text { Aa } \\
\text { Actinobacilus } \\
\text { Actinomycetemcomitans }\end{array}$ & \multirow{2}{*}{$\begin{array}{l}\text { Peptostreptococcus } \\
\text { spp } \\
\end{array}$} & \multirow{2}{*}{$\begin{array}{c}\begin{array}{c}\text { Prevotella } \\
\text { spp }\end{array} \\
\pm\end{array}$} & \multirow{2}{*}{$\begin{array}{c}\text { Porphyromonas } \\
\text { spp }\end{array}$} & \multirow{2}{*}{$\begin{array}{c}\begin{array}{c}\text { Fusobacterium } \\
\text { spp }\end{array} \\
+\end{array}$} & \multirow{2}{*}{$\frac{\text { C. rectus }}{+}$} \\
\hline Penicilina G & \pm & & & & & \\
\hline Amoxicilina & + & + & \pm & \pm & + & + \\
\hline $\begin{array}{l}\text { Amoxicilina/ } \\
\text { a. clavulánico }\end{array}$ & + & + & + & + & + & + \\
\hline Doxiciclina & + & \pm & \pm & \pm & + & + \\
\hline Clindamicina & $\mathrm{O}$ & + & + & + & + & + \\
\hline Metronidazol & O & + & + & + & + & + \\
\hline Macrólidos & \pm & \pm & \pm & \pm & \pm & + \\
\hline $\begin{array}{l}\text { + Mayor del } 80 \% \\
\text { O Menor del } 30 \% \\
\pm \text { Entre el } 30-80 \%\end{array}$ & $\begin{array}{l}\text { de cepas sensibles } \\
\text { de cepas sensibles } \\
\text { de cepas sensibles }\end{array}$ & & & & & \\
\hline
\end{tabular}


el metronidazol como la clindamicina carecen de actividad frente a este microorganismo (46).

\section{Peptostreptococcus spp}

La especie con mayor importancia en infecciones odontógenas es $P$. micros. En general se muestran sensibles a penicilina y otros betalactámicos como amoxicilina, metronidazol y clindamicina (47), si bien entre un 5-15\% de las cepas pueden ser resistentes a clindamicina y hasta un $10-20 \%$ a metronidazol. La actividad de macrólidos y tetraciclinas suele ser algo menor, con tasas de resistencia en torno al 30-50\% $(37,48)$.

\section{Prevotella spp y Porphyromonas spp}

Aproximadamente entre el 30 y el $85 \%$ de las cepas son productoras de betalactamasas, lo que conlleva resistencia a penicilina y a amoxicilina, pero no a amoxicilina/ácido clavulánico ni a otros betalactámicos estables a la acción de estas betalactamasas (39, $47,49)$. La prevalencia de resistencia a tetraciclinas y macrólidos se sitúa en torno al $30-50 \%$ y $80-95 \%$ respectivamente $(47,50,51)$, siendo azitromicina en general el macrólido más activo frente a bacilos gramnegativos anaerobios. El 5-25\% de las cepas son resistentes a clindamicina y menos del 5\% a metronidazol $(47,51)$. En la tabla 3 se muestran los porcentajes de cepas resistentes en el Hospital de Bellvitge entre los años 1996-2000.

\section{Fusobacterium spp}

Tradicionalmente se ha mostrado uniformemente sensible a penicilina. No obstante, se viene detectando un aumento en el porcentaje de cepas productoras de betalactamasas (5-30\%) (39,47,51). Amoxicilina/ácido clavulánico, clindamicina y metronidazol presentan muy buena actividad, con tasas de resistencia inferiores al $5 \%$. La mayoría de los macrólidos y las cefalosporinas son poco activos.

\section{TRATAMIENTO ANTIBIÓTICO DE LA ENFERMEDAD PERIODONTAL}

La antibioterapia sistémica puede ser esencial para la eliminación de bacterias patógenas que invaden los tejidos gingivales así como para reducir y controlar los periodontopatógenos que residen en diferentes localizaciones de la cavidad oral (52). El uso de antibióticos sistémicos se ha mostrado especialmente de utilidad para el tratamiento de periodontitis asociadas a $A$. actinomycetemcomitans en las que el tratamiento mecánico por si solo no consigue erradicar el microorganismo, y en periodontitis refractarias agresivas donde la asociación de antibióticos sistémicos mejora los resultados del tratamiento mecánico solo (53).

Un gran número de estudios han evaluado la eficacia de diversos antimicrobianos en monoterapia o en combinación en el tratamiento de la enfermedad periodontal. Sin embargo, la gran mayoría de éstos no comparan la eficacia del tratamiento mecánico en combinación con antibióticos sistémicos frente al tratamiento mecánico solo. Otro de los problemas que se plantean a la hora de decantarse por un tratamiento antibiótico específico es la práctica ausencia de estudios comparando dos o más antibióticos que nos permitan comparar la eficacia de cada uno de ellos.

Como premisa se puede decir que se deberían utilizar pautas antibióticas que ofrezcan cobertura frente a los principales microorganismos implicados en cada cuadro, ya sean aerobios o anaerobios. Se han obtenido buenas respuestas con amoxicilina/ácido clavulánico, metronidazol, clindamicina, doxiciclina y las combinaciones de metronidazol más amoxicilina y metronidazol más amoxicilina/ácido clavulánico (53, 54).

Varios estudios han mostrado la eficacia de los antibióticos sistémicos en la reducción de los niveles de algunos patógenos. A modo de ejemplo, se ha visto que amoxicilina/ácido clavulánico y metronidazol reducen de forma significativa los niveles de $P$. gingivalis y $B$. Forsythus (55).

TABLA 3.- PORCENTAJE DE CEPAS RESISTENTES EN EL PERÍODO 1996-2000. HOSPITAL DE BELLVITGE (BARCELONA)

\begin{tabular}{|lcc|}
\hline ANTIBIÓTICO & PORPHYROMONAS SPP & PREVOTELI.A SPP \\
\hline Penicilina & $23-38 \%$ & $49-59 \%$ \\
\hline Amoxicilina / á. clavulánico & $0-3 \%$ & $0-3 \%$ \\
\hline Clindamicina & $7-24 \%$ & $12-27 \%$ \\
\hline Metronidazol & $0-2 \%$ & $0-7 \%$ \\
\hline
\end{tabular}


La utilización de antibióticos tópicos o antisépticos también ha dado resultados positivos en algunos estudios. Entre otros se han usado la clorhexidina tópica al $0,2 \%$, povidona yodada al $10 \%$, minociclina gel tópica e hipoclorito sódico al 0,1\% (52).

Acorde con lo recogido en la literatura, los antibióticos de primera linea para el tratamiento de la enfermedad periodontal serían el metronidazol, amoxicilina/ácido clavulánico, doxiciclina, clindamicina y la combinación de metronidazol con amoxicilina $(23,53)$, eligiendo uno u otro en base a la forma clínica y las características del paciente. Assí por ejemplo, en la periodontitis juvenil localizada estaría especialmente indicado la doxiciclina asociada a clorhexicina tópical al 0,2\% mientras que en la enfermedad periodontal del adulto la mejor opción sería amoxicilina/ácido clavulánico o metronidazol, asociando en ambos casos clorhexidina tópica o minociclina gel tópica (23).

\section{SUMMIRY}

Periodontal disease must be considered a chronic bacterial infection. It does not appear to one single bacterial species that is uniquely involved. Rather, periodontal disease seems to be a polymicrobial infection involving several organisms. The bacteria most often associated with periodontal disease are Actinobacillus actinomycetemcomitans, Porphyromonas gingivalis, Prevotella intermedia, Bacteroides forsythus y Treponema denticola. Pharmacodynamics parameters are very useful to select dosing regimens. The increase in prevalence of resistance occurred in some periodontopathogens in the last years has pushed some antibiotics into the background. Positive responses have been reported with amoxicillin/clavulanate, metronidazole, clindamycin, doxycycline and the combination therapy metronidazole plus amoxicillin and metronidazole plus amoxicillin/clavulanate.

\section{KEY WORDS}

Periodontal disease, antibiotics, resistance, pharmacodynamic.

\section{CORRESPONDENCIA}

Dra. Josefina Liñares

Servicio de Microbiología. Hospital Universitario de Bellvitge.

C/ Feixa Llarga, s/n
08907 Hospitalet de Llobregat. Barcelona

Tfno: 93-335 7011

Fax: 93-260 7561

e-mail: fina.linares@csub.scs.es

\section{BIBLIOGRAFÍA}

1.Valle Rodríguez JL, Gómez-Lus Centelles ML, Prieto Prieto J, Liébana Ureña J. Composición y ecología de la microbiota oral. En: Liébana Ureña J. Microbiología oral. Interamericana McGraw-Hill. Madrid 1995; p. 402-7.

2. Chow AW. Infections of the oral cavity, neck, and head. In: Mandell GL, Bennett JE, Dolin R. Principles and Practice of infectious diseases. 5 th edition. Churchill Livingstone. Philadelphia 2000; p. 689-701.

3. Valenti WM, Trudell RB , Bentley DW. Factors predisposing to oropharyngeal colonization with gramnegative bacilli in the aged. N Engl J Med 1978; 298: 1108.

4. Yao ES, Lamont RJ, Leu SP, et al. Interbacterial binding among strains of pathogenic and commensal oral bacterial species. Oral Microbiol Immunol 1996; 11: 35.

5. Bascones Martínez A, Manso Platero FJ, Vadillo Martín JM y Bascones Ilundain J. Tratamiento de las infecciones orofaciales. En: García Sanchez JE, López R, Prieto J. Antimicrobianos en Medicina. Prous Science. Barcelona 1999; 549-57.

6. Loesche WJ, Grossman NS. Periodontal disease as a specific, albeit chronic, infection: diagnosis and treatment. Clin Microbiol Rev 2001; 14: 727-52.

7. Cutler CW, Kalmar JR; Genco CA. Pathogenic strategies of the oral anaerobe, Porphyromonas gingivalis. Trends Microbiol 1995; 3: 45-51.

8. López NJ, Mellado JC, Giglio MS, Leighton GX. Ocurrence of certain bacterial species and morphotypes in juvenile periodontitis in Chile. J Periodontol 1995; 66: 559-67.

9. Mandell RL, Ebersole JL, Socransky SS. Clinical immunologic and microbiologic features of active disease sites in juvenile periodontitis. J Clin Periodontol 1987; 14:53440.

10. Cross DL, Smith GL. Comparison of periodontal disease in HIV seropositive subjetcs and controls. Microbiology, immunology and predictors of disease progression. J Clin Periodontol 22: 569-77.

11. Haffajee AD, Socransky SS, Smith C, Dibart S. Microbial risk indicators for periodontal attachment loss. J Periodontol Res 1991; 26: 293-6. 
12. Papapanou PN, Baelum NV, Luan WM, et al. Subgingival microbiota in adult Chinese: prevalence and relation to periodontal disease progression. J Periodontol 1997; 68: 651-66.

13. Craig WA. Pharmacokinetic/Pharmacodynamic parameters: rationale for antibacterial dosing of mice and men. Clin Infec Dis 1998; 26: 1-12.

14. Jacobs MR. Optimisation of antimicrobial therapy using pharmacokinetic and pharmacodynamic parameters. Clin Microbiol Infect 2001; 7: 589-96.

15. Drusano GL, Craig WA. Relevance of pharmacokinetics and pharmacodynamics in the selection of antibiotics for respiratory tract infections. J Antimicrob Chemother 1997; 9 (suppl 3): 38-44.

16. Thomas JK, Forrest A, Bhavnani SM, Hyatt JM, Cheng $A$, Ballow CH. Pharmacodynamic evaluation of factors associated with the development of bacterial resistance in acutely ill patients during therapy. Antimicrob Agents Chemother 1998; 42: 521-7.

17. Preston SL, Drusano GL, Berman AL et al. Pharmacodynamics of levofloxacin: a new paradigm for early clinical trials. Antimicrob Agents Chemother 1998; 279: 125-9.

18. Moore RD, Lietman PS, Smith CR. Clinical response to aminoglycoside therapy: Importance of the ratio of peak concentration to minimal inhibitory concentration. J Infect Dis 1987; 155: 93-9.

19. Forrest A, Nix DE, Ballow CH, Goss TF, Birmingham MC, Schentag JJ. Pharmacodyna-mics of intravenous ciprofloxacin in seriously ill patients. Antimicrob Agents Chemother 1993; 37: 1073-81.

20. Lacy Mk, Lu W, Xu X, et al. Pharmacodynamic comparisons of levofloxacin, ciprofloxacin, and ampicillin against Streptococcus pneumoniae in an in vitro model of infection. Antimicrob Agents Chemother 1999; 43: 672-7.

21. Lister PD, Sanders CC. Pharmacodynamics of levofloxacin and ciprofloxacin against Streptococcus pneumoniae. J Antimicrob Chemother 1999; 43: 79-86.

22. Andes D. Pharmacokinetic and pharmacodynamic properties of antimicrobials in the therapy of respiratory tract infections. Curr Opin Infect Dis 2001; 14: 165-72.

23. Maestre JR. Infecciones bacterianas mixtas de la cavidad oral. Enferm Infecc Microbiol Clin 2002; 20: 98-101.

24. Kuriyama T, Karasawa T, Nakagawa K, Saiki Y, Yamamoto E, Nakamura S. Bacteriologic features and antimicrobial susceptibiliry in isolates from orofacial odontogenic infections. Oral Surg Oral Med Oral Pathol Oral Radiol Endod 2000; 90: 600-8.

25. Legg JA, Wilson M. Prevalence of betalactamase producing bacteria in subgingival plaque and their sensitivity to Augmentin. Br J Oral Maxillofac Surg 1990; 28: 180-4.

26. Kinder SA, Holt SC, Korman KS. Penicillin resistance in subgingival microbiota associated with adult periodontitis. J Clin Microbiol 1986; 23: 1127-33.

27. Heimdahl A, Von Konow L, Nord CE. Betalactamase producing Bacteroides species in the oral cavity in relation to penicillin therapy. J Antimicrob Chemother 1981; 8: 225-9.

28. Muñoz Bellido JL, Alonso MA, Gutierrez MN. Penicilinas. En: García Sanchez JE, López R, Prieto J. Antimicrobianos en Medicina. Prous Science. Barcelona 1999; 41-71.

29. Marín M, Gudiol F. Antibióticos betalactámicos. Enferm Infecc Microbiol Clin 2003; 21: 42-5.

30. Bascones A, Manso F. Infecciones odontógenas en la cavidad bucal y región maxilofacial. Av Odontoestomatol 1994; 10 (Suppl. A): 5-26.

31. Gilbert DN, Moellering RC, Sande MA. Guía Sanford: Guía de terapéutica antimicrobiana (versión española). Dallas: Antimicrobial Therapy Inc., 2001.

32. Alcaide F, Liñares J, Pallares $\mathrm{R}$ et al. In vitro activities of 22 beta-lactam antibiotics against Penicillin-Resistant and Penicillin-susceptible viridans group streptococci isolated from blood. Antimicrob Agents Chemother 1995; 39: 2243-7.

33. Ioannidou S, Tassios PT, Kotsovili-Tseleni $\AA$ et al. Antibiotic resistance rates and macrolide resistance phenotypes of healthy Greek children. Int J Antimicrob Agents 2001; 17: 195-201.

34. Doern GV, Jane Ferraro M, Brueggemann AB et al Emergence of high rates of antimicrobial resistance among viridans group streptococci in the United States. Antimicrob Agents Chemother 1996; 40: 891-4.

35. Van Winkelhoff AJ, Herrera González D, Winkel EG, Dellemijn-Kippuw N, Vandenbroucke-Grauls CM, Sanz. Antimicrobial resistance in the subgingival microflora in patients with adult periodontitis. A comparison between The Netherlands and Spain. J Clin Periodontol 2000; 27: 79-86.

36. Rodríguez-Avial I, Rodriguez Avial C, Culebras E et al. Distribution of $\operatorname{mef}(A)$ and $\operatorname{erm}(B)$ genes in macrolideresistant blood isolates of viridans group streptococci. J Antimicrob Chemother 2001; 47: 727-8 
37. Mensa J, Gatell JM, Jiménez de Anta MT, Prats G, Domínguez-Gil A. Guía de terapéutica antimicrobiana 2002. Masson. Barcelona.

38. Gordon JM, Walker CB. Current status of systemic antibiotic usage in destructive periodontal disease. J Periodontol 1993; 64: 760-1.

39. Eick S, Pfister W, Fiedler D, Straube E. Clindamycin promotes phagocytosis and intracelluar killing of periodontopathogenic bacteria by crevicular granulocytes: an in vitro study. J Antimicrob Chemother 2000; 46: 583-8.

40. Pérez-Trallero E, Vicente D, Montes M, Marimón JM, Piñeiro L. High proportion of pharyngeal carriers of comensal streptococci resistant to erythromycin in Spanish adults. J Antimicrob Chemother 2001; 48: 225-9.

41. Listgarten MA, Lai CH, Young V. Microbial composition and pattern of antibiotic resistance in subgingival microbial samples from patients with refractory periodontitis. J Periodontol 1993; 64: 155-161.

42. Herrera D, Van Winkelhoff AJ, Dellemijn-Kippuw N, Winkel EG, Sanz M. Betalactamase producing bacteria in the subgingival microflora of adult patients with periodontitis. A comparison between Spain and the Netherlands. J Clin Periodontol 2000; 27: 520-25.

43. Walker CB. The acquisition of antibiotic resistance in the periodontal pathogens. Periodontology 2000 1996; 10: 79-88.

44. Van Winkelhoff AJ, Winkel EG, Barendregt D, DellemijnKippuw, Stijne A, Van der Velden U. Beta-lactamase producing bacteria in adult periodontitis. J Clin Periodontol $1997 ; 538-43$.

45. Madinier IM, fosse TB, Hitzig C, Charbit Y, Hannoun LR. Resistance profile survey of 50 periodontal strains of Actinobacillus actinomycetemcomitans. J Periodontol 1999; 70: 888-92.

46. Kaplan AH, Weber DJ, Oddone E, Perfect JR. Infection due to Actinobacillus actinomycetemcomitans: 15 cases and review. Rev Infect Dis 1989; 11: 46-59.
47. Aldridge KE, Ashcraft D, Camber K, Pierson CL, Jenkins SG, Rosemblatt JE. Multicenter survey of the changing in vitro antimicrobial susceptibilities of clinical isolates of Bacteroides fragilis group, Prevotella, Fusobacterium, Porphyromonas, and Peptostreptococcus species. Antimicrob Agents Chemother 2001; 45: 1238-43.

48. Pankuch GA, Jacobs MR, Appelbaum PC. Susceptibilities of 428 gram-positive and negative anaerobic bacteria to Bay 3118 compared with their susceptibilities to ciprofloxacin, clindamycin, metronidazole, piperacillin, piperacillin-tazobactam and cefoxitin. Antimicrob Agents Chemother 1993; 37:1649-54

49. Fosse T, Madinier I, Hitzig C, Charbit Y. Prevalence of beta-lactamase-producing strains among 149 anaerobic gram-negative rods isolated from periodontal pockets. Oral Microbiol Immunol 1999; 14: 352-7.

50. Finegold SM, Jousimies-Somer H. Recently described clinically important anaerobic bacteria: medical aspects. Clin Infect Dis 1997; 25 (suppl 2): S88-S93.

51. Wexler HM, Molitoris E, Molitoris D. Susceptibility testing of anaerobes: old problems, new options?. Clin Infect Dis 1997; 25 (suppl 2): S275-S278.

52. Slots J. Selection of antimicrobial agents in periodontal therapy. J Periodont Res 2002; 37: 389-98.

53. Walker C, Karpinia K. Rationale for use of antibiotics in periodontics. J Periodontol 2002; 73: 1188-96.

54. Walker C. The supplemental use of antibiotics in periodontal therapy. Compend Contin Educ Dent 1999; 20 (suppl 4): 4-12.

55. Slots J. Systemic antibiotics in the treatment of periodontal disease. Periodontology 2000 2002; 28: 106-76.

56. Rosenberg ES, Torosian JP, Slots J. Microbial differences in 2 clinically distinct types of failures of osseointegrated implants. Clin Oral Implants Res 1991; 2: 135-44. 
